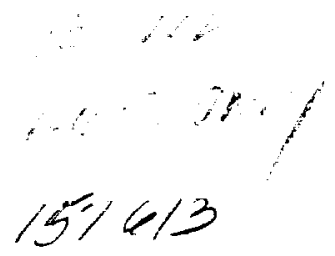

\title{
ABSTRAC'I \\ Infrared Aircraft Measurements of Stratospheric Composition over Antarctica during September 1987
}

G.C. Toon, C.B. Farmer, L.L. Lowes, P.W. Schaper, J.-F. Blavier and R.H. Norton California Institute of Technology. Jet Propulsion Laboratory, 4800 Oak Grove Drive, Pasadena, CA 91109

The JPL Mark IV Interferometer recorded iigh resolution, infared solar spectra from the NASA DC-8 aircraft during fligh:s over Antarctica in September 1987. The atmospheric absorption features in trese spectra have been analyzed to determine the overburdens of $\mathrm{O}_{3}, \mathrm{NO}, \mathrm{NO}_{2}, \mathrm{HNO}_{3}, \mathrm{ClONO} 2, \mathrm{HCl}, \mathrm{HF}, \mathrm{CH}_{4}, \mathrm{~N}_{2} \mathrm{O}$, $\mathrm{CO}, \mathrm{H}_{2} \mathrm{O}$ and $\mathrm{CFC}-12$. The spectra were obtained at latitudes which ranged between $64^{\circ} \mathrm{S}$ and $86^{\circ} \mathrm{S}$, allowing the composition in the interior of the polar vortex to be compared with that at the edge. The figure summarizes the latitude dependence observed for $\mathrm{NO}, \mathrm{NO}_{2}, \mathrm{HNO}_{3}, \mathrm{ClONO}_{2}, \mathrm{HCl}$ and $\mathrm{HF}$. the solid lines South of $65^{\circ} \mathrm{S}$ are derived from the ensemble of Antarctic measurements. The values at $30^{\circ} \mathrm{S}$ were observed on the ferry flight from New Zealand to Hawaii. The dashed lines connecting the two have been interpolated across the region for which we have no measurements. The chemically perturbed region is seen to consist of a "collar" of high $\mathrm{HNO}_{3}$ and $\mathrm{ClONO}_{2}$ surrounding a "core" in which the overburdens of these and of $\mathrm{HCl}$ and $\mathrm{NO}_{2}$ are very low. Clear increases in the overburdens of $\mathrm{HF}$ and $\mathrm{HNO}_{3}$ were observed during the course of September in the vortex core. $\mathrm{HCl}$ and $\mathrm{NO}_{2} \mathrm{ex}-$ hibited smaller, less significant increases. The overburdens of the tropospheric source gases, $\mathrm{N}_{2} \mathrm{O}, \mathrm{CH}_{4}, \mathrm{CF}_{2} \mathrm{Cl}_{2}, \mathrm{CO}$ and $\mathrm{H}_{2} \mathrm{O}$, were observed to be much smaller over Antarctica than at mid-latitudes. This, together with the fact that $\mathrm{HF}$ over Antarctica was more than double its mid-latitude value, suggests that downwelling has occurred.

SUMMARY OF LATIT JDE VARIATIONS OF STRATOSPHERI; TRACE GASES

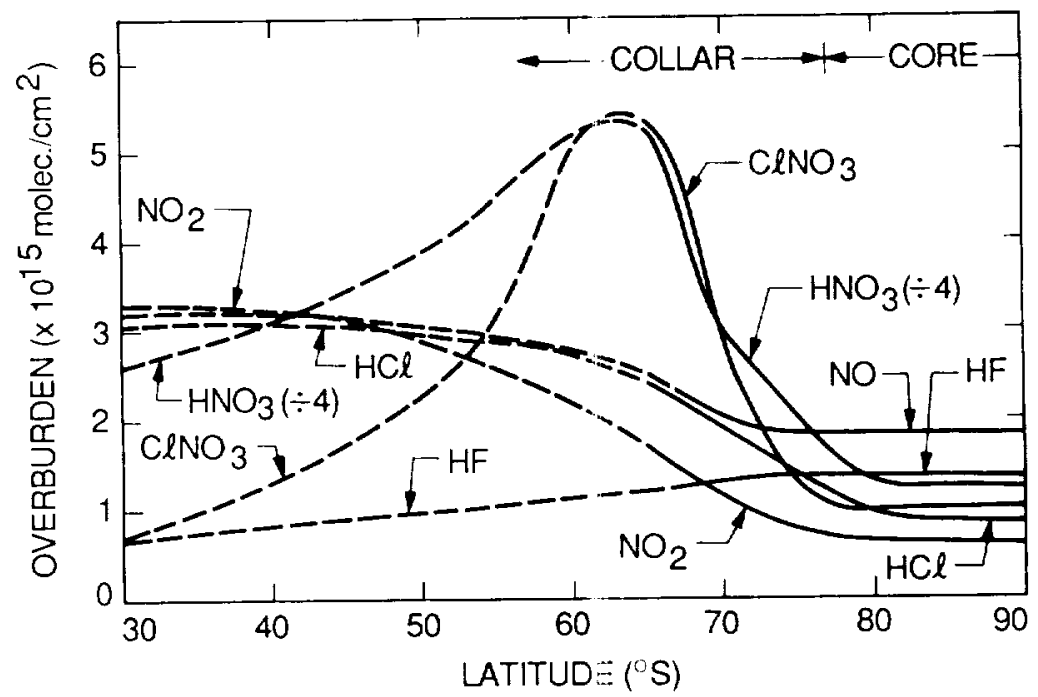

